\title{
Beta-alanine uptake is not a marker for brain astroglia in culture
}

\author{
C. J. CUMMINS, R. A. GLOVER and O. Z. SELLINGER
}

(C.J.C.) Surgical Neurology Branch, National Institute of Neurological and Communicative Disorders and Stroke, National Institutes of Health, Bethesda, MD 20205 and (R.A.G.) Department of Anatomy and (C.J.C. and O.Z.S.) Mental Health Research Institute, The University of Michigan School of Medicine, Ann Arbor, MI 48109 (U.S.A.)

(Accepted January 21st, 1982)

Key words: astrocytes - glial metabolism — beta-alanine - GABA -- amino acid transport

The properties of the beta amino acid transport system were examined in cultivated rat brain astrocytes, using the specific probe, beta-alanine. The uptake of beta-alanine is thought to be glial specific. Beta-alanine was not actively transported and the intracellular accumulation was not altered by coincubation with GABA, alanine, glutamate, or methionine. We suggest therefore that betaalanine is passively taken up by a mechanism distinct from the transport system for GABA.

Brain is a highly heterogeneous tissue, and therefore the role of specific cell types in any dynamic process is difficult to ascertain ${ }^{9}$. Thus, it is of interest to determine the uptake properties of amino acids in pure preparations of each brain cell type.

Astrocytes appear similar to brain in the properties of the amino acid uptake systems ${ }^{11}$. Amino acids are accumulated against a concentration gradient and transport systems discriminate between classes of amino acids on the basis of structural features ${ }^{12}$. Methionine (L-system) and alpha-aminoisobutyrate (A-system) are both actively transported by primary cultures of rat brain astrocytes ${ }^{4-6}$. Furthermore, methionine uptake is altered by elevations in extracellular $\mathrm{K}^{+4,5}$.

Astrocytes have been postulated to transport the beta amino acid analog betaalanine (BALA) by a carrier-mediated system ${ }^{10}$, which is inhibited by GABA ${ }^{7,10}$, suggesting that GABA and BALA may be transported by the same carrier system. Furthermore, BALA uptake has been postulated to be a marker for central astrocytes, and peripheral satellite cells ${ }^{10}$. We present evidence to show that beta-alanine is not actively transported by astrocytes in vitro, and therefore may not be an astrocytic marker.

Astrocytes were grown in culture as previously described ${ }^{3}$. Briefly, cerebra of 3day-old rats are minced, trypsinized, and placed in Eagle's Minimum Essential Medium containing $10 \%$ fetal calf serum. At an initial density of one cerebrum per ten $60 \mathrm{~mm}$ dishes, cultures are confluent ( $10^{4}$ cells) in 12-14 days. Confluent cultures ubiquitously stain with the astrocyte-specific stains phosphotungstic acid hematoxylin, and Cajal's gold sublimate stain ${ }^{3}$, suggesting homotypic purity. Cultures prepared by 
very similar techniques have been shown to stain for glial fibrillary acidic protein ${ }^{1}$ Cultures were used at confluence, $48 \mathrm{~h}$ following the last feeding.

BALA uptake was determined by procedures previously described ${ }^{2}$ for the uptake of methionine ${ }^{4,5}$ and alpha-aminoisobutyrate ${ }^{6}$. Briefly, BALA (Sigma Chemicals, St. Louis, MO) and tracer radiolabeled BALA (beta-[amino- $\left.{ }^{3} \mathrm{H}\right]$ alanine, spec. act. $36 \mathrm{Ci} / \mathrm{mmol}$, New England Nuclear, Boston, MA) were added to approximately $10^{4}$ confluent cells at $37^{\circ} \mathrm{C}$. At various times thereafter, the buffer + BALA was aspirated, the cell monolayer washed with ice-cold $0.9 \% \mathrm{NaCl}$ and disrupted in an aliquot of $0.2 \mathrm{~N}$ perchloric acid (PCA). The PCA-soluble fraction was collected, neutralized and counted. Non-specific binding was determined by rapidly adding icecold buffer + BALA, followed by immediate aspiration, washing and subsequent treatment as above. Experimental values are presented with the non-specific binding subtracted.

The buffer used throughout these experiments contained $5.3 \mathrm{mM} \mathrm{KCl}, 150 \mathrm{mM}$ $\mathrm{NaCl}, 1 \mathrm{mM} \mathrm{CaCl}, 600 \mu \mathrm{M} \mathrm{MgCl}_{2}, 1.6 \mathrm{mM} \mathrm{KH}_{2} \mathrm{PO}_{4}$, and $4.3 \mathrm{mM} \mathrm{Na}_{2} \mathrm{HPO}_{4}, \mathrm{pH}$ 7.2. Protein was determined by the procedure of Lowry et al. ${ }^{8}$.

For neutral amino acids, active transport may be defined as accumulation against a concentration gradient. To quantitate the concentrative accumulation, ([intracellular]/[extracellular] or distribution ratio), cell protein was assumed to constitute $10 \%$ and water to constitute $80 \%$ of the wet weight. Uptake indicated as per mg protein is considered to be equivalent to uptake per $8 \mu \mathrm{l}$ of cell water. We assume that BALA is dispersed in the pool of intracellular water.

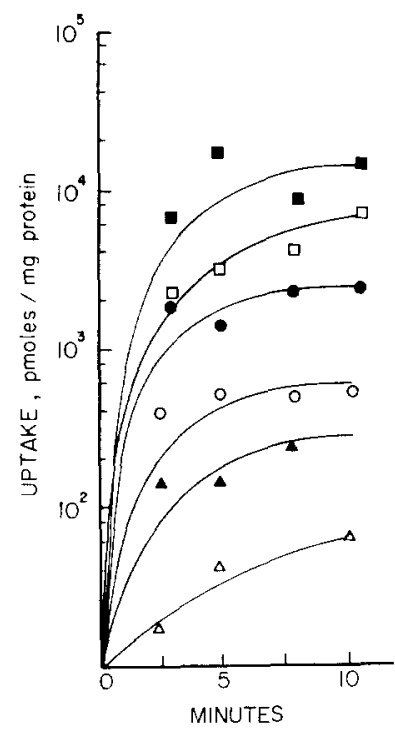

Fig. 1. Beta-alanine uptake was measured as described in Materials and Methods for concentrations of $0.01 \mathrm{mM}(\triangle), 0.05 \mathrm{mM}(\Delta), 0.1 \mathrm{mM}(\bigcirc), 0.5 \mathrm{mM}(\bigcirc), 2.5 \mathrm{mM}(\square)$ and $5.0 \mathrm{mM}(\square)$. The $\log$ of betaalanine uptake is shown as a function of time. The buffer contained $6.9 \mathrm{mM} \mathrm{K} \mathrm{K}^{+}$. Each point represents the mean of duplicate determinations on 3-5 cultures. The standard error was, in each case, less than $15 \%$ of the mean. 


\section{TABLE I}

\section{Distribution ratios of beta-alanine uptake}

Distribution ratios were calculated from the data in Fig. 1. Intracellular water was assumed to be $8 \mu 1 /$ mg protein.

\begin{tabular}{lll}
\hline $\begin{array}{l}\text { Extracellular } \\
(\mathrm{mM})\end{array}$ & $\begin{array}{l}\text { Intracellular } \\
(\mathrm{mM})\end{array}$ & Distribution ratio \\
\hline 0.01 & 0.0075 & 0.75 \\
0.05 & 0.0375 & 0.75 \\
0.10 & 0.075 & 0.75 \\
0.50 & 0.250 & 0.50 \\
2.50 & 0.75 & 0.30 \\
5.0 & 1.88 & 0.375 \\
\hline
\end{tabular}

BALA uptake approached a steady state by 10 min when incubated in a buffer containing $6.9 \mathrm{mM} \mathrm{K}^{+}$(Fig. 1). The calculated distribution ratios for BALA at $10 \mathrm{~min}$ demonstrate that BALA is not actively transported into central astrocytes in vitro (Table I). Johnson and Stephenson?, and Schon and Kelly ${ }^{10}$ showed that rat brain uptake of nanomolar concentrations of BALA was inhibited by GABA in the high micromolar or low millimolar range. Since cross-inhibition between amino acids of the same class is commonly seen with concentration differences of 100 -fold or less ${ }^{12}$, we considered that the specificity of GABA antagonism of BALA uptake was open to question. Thus we examined whether GABA (putatively beta system), glutamate and alanine (putatively A system), or MET (putatively L system) would competitively inhibit the uptake of BALA. BALA at $2.5 \mathrm{mM}$ was tested with GABA, glutamate, alanine or MET, each at $1 \mathrm{mM}$ to determine the effects on the BALA uptake during a 2.5 nin incubation. None of these amino acids inhibited BALA uptake (Table II).

Schon and Kelly ${ }^{10}$ showed that rat cortical astrocytes and satellite cells of sensory ganglia accumulated radioactivity after $20-30 \mathrm{~min}$ incubations with $\left[3-{ }^{3} \mathrm{H}\right]$ beta-

\section{TABLE II}

Effect of amino acids on beta-alanine uptake

Amino acids at $1.0 \mathrm{mM}$ concentration were coincubated with $2.5 \mathrm{mM}$ BALA in confluent cultures of astrocytes for 2.5 minutes in buffer containing $6.9 \mathrm{mM} \mathrm{K}{ }^{+}$. Uptake measurements are means of 3 determinations, \pm S.E.M.

\begin{tabular}{lcl}
\hline Agent & $\begin{array}{l}\text { BALA uptake } \\
\text { (nmoles } / \mathrm{mg} \\
\text { protein } / 2.5 \mathrm{~min} \text { ) }\end{array}$ & \\
\hline BALA alone & $7.2 \pm 0.86$ & 100 \\
+ Methionine & $10.1 \pm 0.86$ & 139 \\
+ GABA & $7.5 \pm 1.60$ & 103 \\
+ Glutamate & $7.9 \pm 0.50$ & 109 \\
+ Alanine & $13.4 \pm 2.11$ & 184
\end{tabular}


alanine. They reported some evidence of metabolism even at short times of incubation, and the radioactivity in their preparation seemed to resist solubilization by aldehyde fixation and dehydration. Their results suggest to us that astrocytes and satellite cells may differentially metabolize BALA, but that there is no evidence of specificity of uptake, except as a passive process secondary to metabolism. Alanine, glutamine, MET and GABA do not compete with BALA for uptake, and thus, primary astrocytes do not appear to have a beta transport system which specifically recognizes BALA. Furthermore, GABA does not inhibit BALA uptake, suggesting that GABA transport and BALA uptake are mediated by distinctly different mechanisms. Beta-alanine is taken up passively, perhaps by simple diffusion, and thus its uptake should not be viewed as an astrocytic marker in vitro.

1 Bock, E., Moller, M., Nissan, C. and Sensenbrenner, M., Glial fibrillary acidic protein in primary astroglial cell cultures derived from newborn rat brain, FEBS Lett., 83 (1977) 201-211.

2 Cummins, C. J., The effect of extracellular potassium on the intermediary metabolism of primary astrocytes in vitro, Dissertation Abstracts, 1977, The University of Michigan.

3 Cummins, C. J. and Glover, R. A., Propagation and histological characterization of a homotypic population of astrocytes derived from neonatal rat brain, J. Anat., 125 (1978) 117-125.

4 Cummins, C. J., Glover, R. A. and Sellinger, O. Z., Neuronal cues regulate uptake in cultured astrocytes, Brain Research, 170 (1979) 190-193.

5 Cummins, C. J., Glover, R. A. and Sellinger, O. Z., Potassium modulation of methionine uptake in astrocytes in vitro, Submitted for publication.

6 Cummins, C. J., Glover, R. A. and Sellinger, O. Z., Alpha-aminoisobutyric acid uptake in primary cultures of astrocytes, Submitted for publication.

7 Johnson, G. and Stephenson, A., Inhibition of the glial uptake of beta alanine in rat brain slices, Brain Research, 102 (1976) 374-378.

8 Lowry, O. H., Rosebrough, N., Farr, A. and Randall, R., Protein measurement with the Folin phenol reagent, J. biol. Chem., 193 (1951) 265-275.

9 Lund-Andersen, H., Kjeldsen, C., Hertz, L. and Bronsted, H., Uptake of glucose analogs by rat brain cortex slices: $\mathrm{Na}^{+}$-independent membrane transport, J. Neurochem., 27 (1976) 369-373.

10 Schon, F. and Kelly, J., Selective uptake of $\left[{ }^{3} \mathrm{H}\right]$ beta-alanine by glia: association with the glial uptake system for GABA, Brain Research, 86 (1975) 243-257.

11 Schousboe, A., Hertz, L. and Svenneby, G., Uptake and metabolism of GABA in astrocyte cultures from dissociated brain hemispheres, Neurochem. Res., 32 (1977) 719-726.

12 Sershen, H. and Lajtha, A., Inhibition pattern by analogs indicates the presence of at least ten or more transport systems for amino acids in brain cells, J. Neurockem., 32 (1979) 719-726. 